\title{
Malignant Kidney Neoplasm
}

National Cancer Institute

\section{Source}

National Cancer Institute. Malignant Kidney Neoplasm. NCI Thesaurus. Code C7548.

Primary or metastatic malignant neoplasm involving the kidney. 